\title{
Esterification of M. sagu bark as an adsorbent for removal of emulsified oil
}

\begin{abstract}
Sago or Metroxylon sagu, harvested in Sarawak, Malaysia, is a low-cost, natural adsorbent. The sago bark (SB) from M. sagu was investigated for adsorptive removal of emulsified oil in palm oil mill effluent (POME). Hydrophobicity of this sorbent in aqueous state was improved via esterification process. The esterification of SB was conducted at ratio of sago bark to stearic acid (SA) by 1:1, 4:1, and 7:1; percentage catalyst of 5,10, and 15; and refluxing time $1,4.5$, and $8 \mathrm{~h}$; respectively. These parameters were analysed using full central composite design (CCD) of response surface methodology (RSM). The adjusted R-squared value of 0.9509 showed that the regression model fit the data well. The predicted R-squared value (0.9168) also indicated that the prediction of experimental data was satisfactory. Hydrophobicity test, FTIR, and SEM were carried out to characterise the esterified sago bark (ESB). Results showed that esterification process successfully increased the hydrophobicity of sago bark by $42.2 \%$ and oil removal efficiency in POME by 50.2\%. A developed twofactor interaction (2FI) model showed that the preparation conditions of 1:1 SB:SA, 15\% catalyst, and $8 \mathrm{~h}$ refluxing time afforded ESB with the maximum oil removal efficiency of up to $95.52 \%$ in POME. The esterification of SB successfully improved the oil adsorptivity for the removal of emulsified oil in POME.
\end{abstract}

Keyword: M. sagu; Esterification; Stearic acid; Oil sorbent; Palm oil mill effluent 